\title{
Evaluation of the potential of different high calorific waste fractions for the preparation of solid recovered fuels
}

\author{
Diego Garcés ${ }^{a}$, Eva Díaz ${ }^{a}$, Herminio Sastre ${ }^{a}$, Salvador Ordóñez ${ }^{a}, *$ José Manuel González-LaFuente ${ }^{b}$ \\ ${ }^{a}$ Department of Chemical and Environmental Engineering, University of Oviedo, Julián Clavería s/n, 33006 Oviedo, Spain \\ ${ }^{\mathrm{b}}$ COGERSA, S.A.U. La Zoreda, Serín, 33697 Gijón, Spain
}

\section{A R T I C L E I N F O}

\section{Article history:}

Received 22 May 2015

Revised 20 August 2015

Accepted 20 August 2015

Available online 28 August 2015

\section{Keywords:}

Solid recovered fuel

ELV wastes

Heating values

Modelling

Bulky wastes

Packaging wastes

\begin{abstract}
A B S T R A C T
Solid recovered fuels constitute a valuable alternative for the management of those non-hazardous waste fractions that cannot be recycled. The main purpose of this research is to assess the suitability of three different wastes from the landfill of the local waste management company (COGERSA), to be used as solid recovered fuels in a cement kiln near their facilities. The wastes analyzed were: End of life vehicles waste, packaging and bulky wastes. The study was carried out in two different periods of the year: November 2013 and April 2014. In order to characterize and classify these wastes as solid recovered fuels, they were separated into homogeneous fractions in order to determine different element components, such as plastics, cellulosic materials, packagings or textile compounds, and the elemental analysis (including chlorine content), heavy metal content and the heating value of each fraction were determined. The lower heating value of the waste fractions on wet basis varies between $10 \mathrm{MJ} \mathrm{kg}^{-1}$ and $42 \mathrm{MJ} \mathrm{kg}^{-1}$. One of the packaging wastes presents a very high chlorine content $(6.3 \mathrm{wt} . \%)$ due to the presence of polyvinylchloride from pipe fragments, being the other wastes below the established limits. Most of the wastes analyzed meet the heavy metals restrictions, except the fine fraction of the end of life vehicles waste. In addition, none of the wastes exceed the mercury limit content, which is one of the parameters considered for the solid recovered fuels classification. A comparison among the experimental higher heating values and empirical models that predict the heating value from the elemental analysis data was carried out. Finally, from the three wastes measured, the fine fraction of the end of life vehicles waste was discarded for its use as solid recovered fuels due to the lower heating value and its high heavy metals content. From the point of view of the heating value, the end of life vehicles waste was the most suitable residue with a lower heating value of $35.89 \mathrm{MJ} \mathrm{kg}^{-1}$, followed by the packaging waste and the bulky waste, respectively. When mixing the wastes studied a global waste was obtained, whose classification as solid recovered fuels was NCV 1 $\mathrm{Cl} 3 \mathrm{Hg}$ 3. From the empirical models used for calculating higher heating value from elemental content, Scheurer-Kestner was the model that best fit the experimental data corresponding to the wastes collected in November 2013, whereas Chang equation was the most approximate to the experimental heating values for April 2014 fractions. This difference is due to higher chlorine content of the second batch of wastes, since Chang equation is the only one that incorporates the chlorine content.
\end{abstract}

(C) 2015 Elsevier Ltd. All rights reserved.

\section{Introduction}

The European legislation about waste disposal has established a hierarchy of available technologies for the treatment or management of wastes: prevention, minimization, reuse, recycling, energy recovery and disposal (European Comission, 2008). Under EU policy, recycling of materials is preferable to energy recovery, and landfilling is the last option to be considered. In Europe, $481 \mathrm{~kg}$ of waste generated per capita in 2013 (Eurostat, 2013), only

\footnotetext{
* Corresponding author.

E-mail address: sordonez@uniovi.es (S. Ordóñez).
}

$130 \mathrm{~kg}$ were recycled, whereas $122 \mathrm{~kg}$ were incinerated and $147 \mathrm{~kg}$ were landfilled. These data point out the difficulties in the municipal solid waste (MSW) management. Although recyclable fractions such as paper, plastic and glass, and the biodegradable fraction of MSW can be either recycled or used as raw material for biological treatments, not all waste materials can be recycled. Moreover, the material sorting and recycling chains generate a large amount of residues which cannot be recycled and usually go directly to the landfill, although several of these materials present high heating values (Arena and Di Gregorio, 2014; Nasrullah et al., 2014). Waste landfilling presents several drawbacks. Firstly, the great volume of wastes accumulated, which could represent 
2/3 of the initial volume of waste (Montejo et al., 2011), with the subsequent landfill space needings. Secondly, the potential environmental pollution caused either by the methane emissions generated by anaerobic degradation of organic wastes, or the heavy metals leached from the waste of landfill (Sánchez et al., 2009). In addition, landfilling leads to huge loss of material and energy resources. Among the possible alternatives, waste combustion (in specific facilities or in energy-intensive industrial processes) is an option to solve the problems of space and the loss of valuable stuffs. In fact, once the recyclable materials have been recovered, the refuse derived fuel (RDF) or solid recovered fuel (SRF) combustion is an alternative to be considered (Lombardi et al., 2015; Montejo et al., 2011; Rada et al., 2008, 2014; Samolada and Zabaniotou, 2014). The use of fractions of this material as fuel could have several advantages as the decreasing use of landfill, and the replacement of fossil fuels with the corresponding reduction of greenhouse gas emissions (Burnley et al., 2011). The use of wastes as RDF leads to a product which can be burned in a planned plant with higher thermal efficiencies than the obtained in a conventional incineration plant (Burnley et al., 2011). In fact, the production of primary energy coming from waste incineration has shown a continuous increase in the last years (Ruiz Romero et al., 2012). At this point, it has been even demonstrated that these waste-to-energy approaches can have a positive effect in the global economy of a region/country, as demonstrated for the case of Greece in the macro-economic study recently reported (Psomopoulos et al., 2014).

The RDF/SRF generated from non-hazardous waste can come from multiple sources, such as industrial waste, commercial waste, waste from construction and demolition, sewage sludge, and/or MSW (Rada and Andreottola, 2012; Ragazzi and Rada, 2012). In Europe, the mechanical/biological treatment (MBT) is an increasing option for the RDF/SRF production for industrial purposes. The aim of MBT is to minimize the environmental impact associated with landfilling of biodegradable waste and to obtain additional value from waste by recovery of recyclable materials such glass, metals, waste-derived solid fuels fractions (Rada and Andreottola, 2012; Ragazzi and Rada, 2012).

Concerning to the SRF applications, several options for SRF utilization and conversion to energy have been already used or proposed for the future: thermal conversion device, which could include fluidized bed combustion, gasification or pyrolysis, fluidized bed boilers of some gasification plants, co-combustion in coal fired boilers, co-gasification with coal and biomass and cofuel in cement kilns (Psomopoulos, 2014).

Using SRF in combustion processes in dedicated plants may have several limitations since it is not a zero waste method (resulting ash disposal containing heavy metals), and it is a source of GHG, and furans and dioxins emissions (Samolada and Zabaniotou, 2014). However, using SRF as co-fuel in cement kilns has strengths compared to in comparison to other combustion processes: it is a zero waste method, achieving a reduction in the consumption of conventional fossil fuels with simultaneous material recovery (Samolada and Zabaniotou, 2014). The cement industry, with $30-40 \%$ of the total costs due to the energy, is one of the main industrial activities interested in alternative fuels (Tsiliyannis, 2012). Use of SRF in cement kilns effectively contributes to the goals of an Integrated Management Scheme, leading to zero wastes for landfilling. Residual ash, always produced in common combustion units, is effectively incorporated in the cement product. This method has other serious environmental benefits related to the minimization of toxic combustion pollutants (dioxins and furans) due to complete oxidation and to particularly favorable reaction conditions $\left(2000^{\circ} \mathrm{C}\right)$ compared to combustion in dedicated plants usually operated al lower temperatures (Samolada and Zabaniotou, 2014).
SRF can be distinguished from RDF in the fact that it is produced to reach a standard such as CEN/343 (EN 15359). In this way, the European Committee for Standardisation (CEN) has selected as key technical performance indicators of the SRF: lower heating value, residual chlorine content and mercury content (Rada and Andreottola, 2012). The concentration of chlorine in SRF is especially relevant since elevated concentration could create both technical problems and environmental concerns, such as generation of acid gas emissions and formation of polychlorinated dibenzodioxins (PCDDs) (Velis et al., 2012). In order to obtain a waste that can be used as SRF in cement plants, particle size is other of the key parameters. Alternative fuel injection in the main burner of a cement kiln requires that the particle size is less than $10 \mathrm{~mm}$. For use as fuel for injection into precalciner, the particle size should be less than $100 \mathrm{~mm}$, preferably with a two-dimensional geometry.

In this way, COGERSA, waste management Company in Asturias (1 million habitants region in the North of Spain) evaluated the possibility of profiting non-recyclable wastes which are nowadays landfilled. The susceptible residues to be recovered as SRF considered in the present study, were wastes (including mixtures of materials) from mechanical treatment of wastes (List of Wastes, LOW 1912 12), including wastes not otherwise specified from End-of-life vehicles and their components (LOW 1601 99), refuse from a sorting plant of municipal packaging waste separately collected (LOW 150106 ), and refuse from preparation of municipal bulky waste for recycling (LOW 2003 07). The amounts generated from these wastes in COGERSA facilities (2013) were 17,410 tons of end of live vehicles waste (ELV), 7186 tons of bulky waste and 3277 tons of packaging waste.

The main purpose of this work is to assess the suitability of three non-recyclable wastes generated in our region and, nowadays landfilled, as SRF to be used as co-fuel in a cement kiln near COGERSA facilities. Samples of ELV, bulky, and packaging wastes were taken in two different periods of the years 2013 and 2014 (November 2013 and April 2014), with the aim of including the seasonality as studied variable. For each fraction, both chemical and calorimetric analyses were carried out in order to classify the different wastes from COGERSA as SRF according to the rules established by EN 15359 being the main analyzed parameters, lower heating value (LHV) on wet basis, mercury and chlorine content as shown in Table 1. Likewise, empirical models were applied in order to predict the higher heating values (HHV) of these fractions from chemical composition.

\section{Experimental}

\subsection{Sampling and materials}

The samples analyzed in this study from the three selected wastes (ELV, bulky and packaging wastes) were supplied by COGERSA. In order to maintain the representativeness of the industrial samples, sample mass for wastes studied were reduced by the quartering method in COGERSA facilities (Environmental Protection Agency, Ireland, 1996). This method consists in dividing a pile of each waste into four quarters and either pair of opposite corners is removed, repeating this until the desired sample size is obtained. Then, the samples obtained were milled in an industrial milling twice to ensure a particle size below $100 \mathrm{~mm}$ (required for use as fuel in cement kilns) and were finally deposited in big bags of $1 \mathrm{~m}^{3}$. A portion of $5 \mathrm{~kg}$ of each waste sample was manually taken by COGERSA workers from big bags before mentioned, and submitted to the laboratory for further analysis. The sampling was carried out in November 2013 and April 2014 and was performed for a week in each occasion. In order to take representative analysis samples of each type of waste, the 
Table 1

Waste classification criteria as SRF, according to EN 15359.

\begin{tabular}{|c|c|c|c|c|c|c|c|}
\hline \multirow[t]{2}{*}{ Parameter } & \multirow[t]{2}{*}{ Statistical measure } & \multirow[t]{2}{*}{ Unit } & \multicolumn{5}{|l|}{ Class } \\
\hline & & & 1 & 2 & 3 & 4 & 5 \\
\hline Lower heating value & Mean value & $\mathrm{MJ} \mathrm{kg}^{-1}$ & $\geqslant 25$ & $\geqslant 20$ & $\geqslant 15$ & $\geqslant 10$ & $\geqslant 3$ \\
\hline Chlorine content & Mean value & $\%(w / w)$ & $\leqslant 0.2$ & $\leqslant 0.6$ & $\leqslant 1.0$ & $\leqslant 1.5$ & $\leqslant 3$ \\
\hline Mercury content & Mean value & $\mathrm{mg} \mathrm{MJ}^{-1}$ & $\leqslant 0.02$ & $\leqslant 0.03$ & $\leqslant 0.08$ & $\leqslant 0.15$ & $\leqslant 0.50$ \\
\hline
\end{tabular}

sampling procedure was performed according to EN 15413 standard. This procedure consists of four successive stages as shown in Fig. 1: separation into homogeneous fractions, drying, particle size reduction, and subsampling.

According to this standard procedure, in cases of visible heterogeneity, samples may be separated into different fractions, especially if this can make easier the subsequent operations of particle size reduction, homogenization and subsampling. Therefore, in this study, all the waste samples were manually sorted into different material categories or fractions as shown in Table $2.20 \mathrm{~g}$ of each different fraction are obtained for further steps. The fractions were weighed individually to determinate the overall weight contribution of each fraction in each waste as shown in Table 2. Standard deviations for these data are also shown in Table 2. These fractions were previously dried to not include the effect of the seasonal variations of waste moistures.

In order to prepare the analysis samples, portions of $10 \mathrm{~g}$ of each waste fraction were dried at $105^{\circ} \mathrm{C}$ for over $2 \mathrm{~h}$ in a drying stove to remove moisture, determining in this way the moisture content of each fraction. In the specific case of heavy metal analysis, fractions of $10 \mathrm{~g}$ were dried at room temperature for $24 \mathrm{~h}$ to avoid losses of mercury according to EN 15413.

Waste fractions previously dried were shredding and dividing according to the EN 15413. The particle size reduction is generally a multi-step operation involving different techniques, depending on the physical characteristics of the sample and the required final particle size. In this study, three milling techniques were tested:

- Grinding/Milling. Involves the use of an electric grinder, reducing the size prior using scissors. This technique is used for hard materials to reduce particle size to the order of millimeters. This type of milling was used for the cellulosic fraction of the bulky waste.

- Cryogenic grinding. This technique is recommended when the sample includes a big amount of plastics. Materials were immersed in liquid nitrogen contained in a Dewar container for $10 \mathrm{~min}$ and, subsequently, these materials were milled using an electric grinder. This sort of milling technique was used for the plastic fraction and the fraction of foams of the ELV waste and the fraction of foams of the bulky waste.

- Manual cutting. This technique is indicated when the material of the sample is not hard enough to allow grinding or milling. In this case, this technique was used for the textile fractions of
Table 2

Fractional composition of different wastes considered in this study.

\begin{tabular}{|c|c|c|c|c|c|}
\hline \multirow[t]{2}{*}{ Waste } & \multirow[t]{2}{*}{ Fraction } & \multicolumn{2}{|c|}{$\begin{array}{l}\text { Composition } \\
\text { November } 2013\end{array}$} & \multicolumn{2}{|c|}{$\begin{array}{l}\text { Composition April } \\
2014\end{array}$} \\
\hline & & $\begin{array}{l}\text { Average } \\
(\%)\end{array}$ & $\begin{array}{l}\text { Std. dev. } \\
(\%)\end{array}$ & $\begin{array}{l}\text { Average } \\
(\%)\end{array}$ & $\begin{array}{l}\text { Std. dev. } \\
(\%)\end{array}$ \\
\hline \multirow[t]{4}{*}{ ELV } & Fine & & & n.a & n.a \\
\hline & Plastics & 60.78 & 13.50 & 69.22 & 8.07 \\
\hline & Foams & 18.56 & 9.78 & 4.92 & 2.38 \\
\hline & Textile & 20.66 & 4.68 & 25.86 & 6.24 \\
\hline \multirow[t]{4}{*}{ Packaging } & Packaging & 56.88 & 17.34 & 29.71 & 20.88 \\
\hline & Soft plastics & 17.47 & 1.74 & 13.89 & 6.23 \\
\hline & $\begin{array}{l}\text { Cellulosic } \\
\text { (paper) }\end{array}$ & 16.61 & 3.52 & 17.38 & 15.68 \\
\hline & Textile & 9.04 & 6.95 & 39.02 & 17.96 \\
\hline \multirow[t]{4}{*}{ Bulky } & Foams & 17.35 & 8.48 & 17.26 & 4.03 \\
\hline & $\begin{array}{l}\text { Cellulosic } \\
\text { (wood) }\end{array}$ & 55.30 & 9.54 & 49.42 & 11.88 \\
\hline & Textile & 27.35 & 3.22 & 25.70 & 11.86 \\
\hline & Plastics & - & - & 7.62 & 13.20 \\
\hline
\end{tabular}

Average \pm standard deviations (\%) based on $n=3$ during fractional composition analysis.

the ELV and bulky wastes and all the fractions of the packaging waste. These materials were cut using scissors.

Once reduced particle size of the waste fractions, subsamples of $10 \mathrm{~g}$ of each fraction were selected, using the same quartering process as that used for the samples sent to the laboratory.

\subsection{Analysis}

In this work, samples of twelve fractions of non-recyclable wastes were characterized as solid fuels and their properties were evaluated. In this way, proximate analysis (moisture and ash) and elemental analysis were performed, and chlorine as well as heavy metal content, and heating value were determined.

Ash content was measured introducing portions of $1-1.5 \mathrm{~g}$ of each waste fraction in a muffle furnace through the loss on ignition at $550{ }^{\circ} \mathrm{C}$ for $2 \mathrm{~h}$.

Ultimate analysis ( $\mathrm{C}, \mathrm{H}, \mathrm{N}, \mathrm{S}$ contents) was carried out according to EN 15407 using an elemental analyzer (Elementar Vario EL) employing samples of 0.1-0.2 g. This device performs the complete

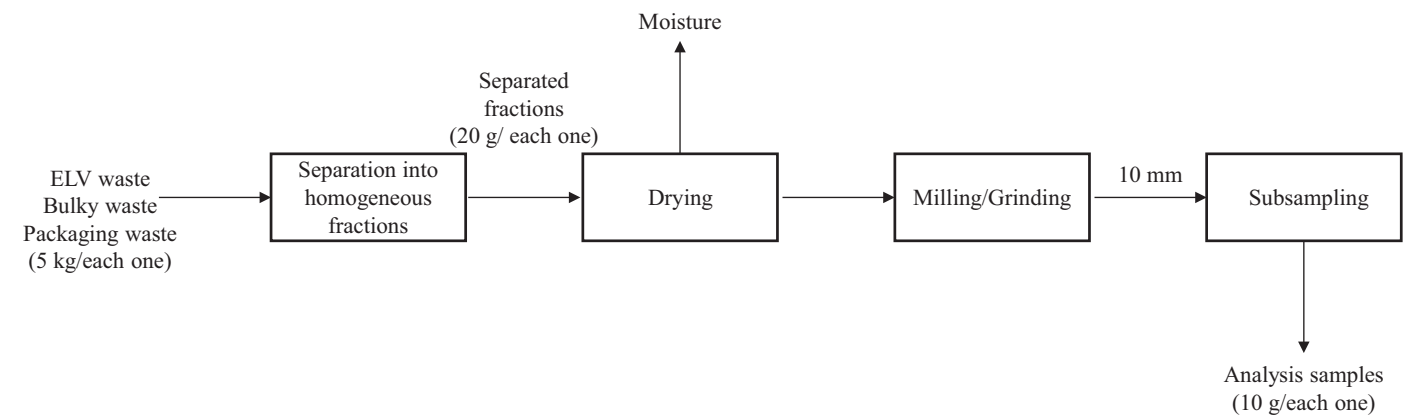

Fig. 1. Procedure of sample preparation of wastes analyzed in laboratory. 
oxidation of the sample at $1000{ }^{\circ} \mathrm{C}$ whereas a helium stream carries the flue gas to a Thermal Conductivity Detector (TCD) for quantifying. The determination of oxygen content, necessary for the calculation of heating values through empirical models, was approximately calculated by difference using Eq. (1).

$$
\begin{aligned}
\mathrm{O}(\mathrm{wt} . \%)= & 100-\mathrm{H}(\text { wt. } \%)-\mathrm{C}(\mathrm{wt} . \%)-\mathrm{N}(\text { wt. } \%) \\
& -\mathrm{S}(\text { wt. } \%)-\text { Ash }(\text { wt. } \%)
\end{aligned}
$$

Chlorine was collected according to EN 15408 using the same adiabatic calorimeter employed for the determination of LHV. Chlorine gas was collected in a $10 \mathrm{~mL}$ water solution into the calorimetric bomb after it was produced through perfect combustion of the sample (ca. $1.000 \mathrm{~g}$ ). Chlorine content of each sample was determined using a Crison selective ion electrode (Virmond et al., 2012). The reliability of the electrode was ensured by using a control sample of a known concentration of 2,6-dichloroqui none-4-chloroimide.

According to EN 15411, the determination of mercury and other heavy metals was carried out using an Agilent 7500c inductively coupled plasma mass spectrometry (ICP-MS) after acid digestion in a microwave digester of a $0.25 \mathrm{~g}$ sample with $10 \mathrm{~mL}$ of $\mathrm{HNO}_{3}$.

The HHV on dry basis for each one of the fractions (ca. $1.000 \mathrm{~g}$ ) was measured using an adiabatic calorimeter (IKA C4000) according to EN 15400 for the determination of the heating value of SRF. First, periodic calibrations with benzoic acid (HHV $=26.46 \mathrm{MJ} \mathrm{kg}^{-1}$ ) were performed. All analyses were, at least, twice replicated.

LHV is calculated assuming that all the water of the sample is present as vapor after the combustion of the sample. To determine the LHV of the samples, it is necessary to know the hydrogen, oxygen and nitrogen content in the sample.

The LHV can be calculated from the HHV obtained experimentally for each fraction (EN 15400; Telmo and Lousada, 2011):

$$
\begin{aligned}
\mathrm{LHV}_{\text {wet }}= & {\left[\mathrm{HHV}_{\mathrm{dry}}-212.2 \mathrm{H}_{\mathrm{dry}}-0.8\left(\mathrm{O}_{\mathrm{dry}}+\mathrm{N}_{\mathrm{dry}}\right)\right](1-W / 100) } \\
& -0.02443 \mathrm{~W}
\end{aligned}
$$

where $\mathrm{LHV}_{\text {wet }}$ and $\mathrm{HHV}_{\text {dry }}$ are the Lower Heating Value on wet basis and the Higher Heating Value on dry basis for each sample, expressed in $\mathrm{kJ} / \mathrm{kg} ; \mathrm{H}_{\mathrm{dry}}, \mathrm{O}_{\mathrm{dry}}$ and $\mathrm{N}_{\mathrm{dry}}$ is the percentage by weight of hydrogen, oxygen and nitrogen on dry basis, respectively; $W$ is the moisture content (in percentage by weight) in each sample.

\section{Results and discussion}

\subsection{Characterization of selected waste fractions}

Table 3 shows the average values obtained for elemental analysis, and ash and moisture contents of the samples of each one of the fractions considered in this work.

The moisture content of the waste fractions differs considerably with the considered month. For the ELV wastes, the highest content of moisture in the sample collected in April 2014 is remarkable, being this fact more marked for the plastic fraction. These results are consistent with average rainfall data in the period January-March 2014 (644.8 $\mathrm{mm}$ ) against the data obtained in the period August-October 2013 (258.8 mm) as shown in Fig. 2 (AEMET, 2014). This fact suggests that the moisture content is influenced greatly by both the manufacturing and atmospheric conditions, thus different conditions in the storage of the different fractions could result in large deviations in final moisture content. For example, in COGERSA facilities, whereas bulky waste is stored outside near grinding area, packaging waste is always kept in a closed storage With regard to fractional composition, plastics are, after metallic components (not analyzed in this case), the major component in the ELV waste, in agreement with previous works about this type of wastes (Mirabile et al., 2002). Concerning the packaging and

\begin{tabular}{|c|c|c|c|c|c|c|c|c|c|c|}
\hline Waste & Fraction & & $\mathrm{C}$ & $\mathrm{N}$ & $\mathrm{H}$ & 0 & $\mathrm{Cl}$ & $\mathrm{S}$ & Ash cont & Moisture $^{\mathrm{a}}$ \\
\hline \multirow[t]{7}{*}{ ELV } & Fine & N13 & $8.30 \pm 12$ & $0.32 \pm 67$ & $1.07 \pm 7.6$ & $19.1 \pm 4.5$ & $0.1 \pm 24$ & $0.72 \pm 16$ & $70.5 \pm 1.2$ & $3.76 \pm 4.6$ \\
\hline & Plastics & N13 & $78.2 \pm 5.3$ & $0.45 \pm 34$ & $10.7 \pm 1.3$ & $4.14 \pm 5.5$ & $0.07 \pm 21$ & $0.51 \pm 11$ & $6.04 \pm 8.9$ & $0.38 \pm 13$ \\
\hline & & A14 & $76.5 \pm 1.5$ & $0.10 \pm 34$ & $13.6 \pm 3.6$ & $8.79 \pm 7.4$ & $0.06 \pm 23$ & $0.03 \pm 15$ & $1.00 \pm 21$ & $9.00 \pm 12$ \\
\hline & Foams & N13 & $52.8 \pm 3.1$ & $3.92 \pm 55$ & $7.15 \pm 3.5$ & $8.95 \pm 6.1$ & $0.23 \pm 12$ & $0.44 \pm 12$ & $26.8 \pm 4.5$ & $2.54 \pm 8.9$ \\
\hline & & A14 & $58.3 \pm 2.1$ & $6.93 \pm 15$ & $7.56 \pm 7.6$ & $15.6 \pm 11$ & $0.73 \pm 36$ & $0.62 \pm 9.4$ & $11.0 \pm 13$ & $3.30 \pm 42$ \\
\hline & Textile & N13 & $54.6 \pm 4.3$ & $2.36 \pm 43$ & $4.13 \pm 8.6$ & $2.39 \pm 3.3$ & $2.65 \pm 11$ & $0.41 \pm 9.4$ & $36.1 \pm .7$ & $2.55 \pm 17$ \\
\hline & & A14 & $58.7 \pm 3.1$ & $1.11 \pm 25$ & $4.77 \pm 8.2$ & $23.8 \pm 8.4$ & $0.09 \pm 21$ & $0.56 \pm 39$ & $11.0 \pm 15$ & $2.70 \pm 32$ \\
\hline \multirow[t]{2}{*}{ ELV global } & Aver. Val. & N13 & 68.59 & 1.49 & 8.67 & 4.67 & 0.63 & 0.48 & 16.10 & 1.23 \\
\hline & & A14 & 71.00 & 0.70 & 11.01 & 13.01 & 0.10 & 0.20 & 4.08 & 7.09 \\
\hline \multirow[t]{8}{*}{ Packaging } & Packaging & N13 & $72.2 \pm 6.1$ & $0.21 \pm 45$ & $8.67 \pm 9.6$ & $12.6 \pm 5.8$ & $0.08 \pm 18$ & $0.28 \pm 14$ & $6.07 \pm 8.6$ & $5.33 \pm 9.5$ \\
\hline & & A14 & $80.0 \pm 2.1$ & $0.13 \pm 31$ & $14.3 \pm 5.7$ & $4.04 \pm 8.9$ & $12.0 \pm 12$ & $0.52 \pm 14$ & $1.00 \pm 19$ & $0.30 \pm 12$ \\
\hline & Soft plastics & N13 & $72.1 \pm 6.2$ & $1.18 \pm 31$ & $10.8 \pm 7.9$ & $8.6 \pm 7.4$ & $0.12 \pm 32$ & $0.84 \pm 11$ & $6.53 \pm 7.6$ & $1.40 \pm 12$ \\
\hline & & A14 & $78.7 \pm 1.4$ & $0.53 \pm 22$ & $13.2 \pm 5.8$ & $4.91 \pm 10$ & $0.28 \pm 12$ & $0.68 \pm 9.3$ & $2.00 \pm 11$ & $1.40 \pm 21$ \\
\hline & Cellulosic & N13 & $37.4 \pm 5.2$ & $0.59 \pm 18$ & $5.14 \pm 9.6$ & $30.3 \pm 4.3$ & $0.14 \pm 12$ & $0.96 \pm 9.8$ & $25.7 \pm 7.1$ & $9.21 \pm 18$ \\
\hline & & A14 & $31.3 \pm 2.3$ & $1.12 \pm 21$ & $0.33 \pm 7.2$ & $54.0 \pm 5.2$ & $0.08 \pm 36$ & $0.31 \pm 18$ & $13.0 \pm 6.5$ & $9.80 \pm 9.5$ \\
\hline & Textile & N13 & $56.8 \pm 7.7$ & $0.73 \pm 12$ & $4.03 \pm 9.7$ & $32.5 \pm 5.3$ & $0.08 \pm 22$ & $0.51 \pm 9.9$ & $5.5 \pm 11$ & $1.95 \pm 23$ \\
\hline & & A14 & $55.3 \pm 0.4$ & $3.21 \pm 28$ & $6.78 \pm 5.2$ & $22.1 \pm 3.4$ & $6.84 \pm 16$ & $1.61 \pm 14$ & $11.0 \pm 9.1$ & $4.10 \pm 2.3$ \\
\hline \multirow[t]{2}{*}{ Packaging global } & Aver. Val. & N13 & 65.00 & 0.49 & 8.03 & 16.62 & 0.10 & 0.51 & 9.35 & 4.98 \\
\hline & & A14 & 61.70 & 1.55 & 8.79 & 19.89 & 6.28 & 0.94 & 7.13 & 3.59 \\
\hline \multirow[t]{7}{*}{ Bulky } & Foams & N13 & $58.1 \pm 4.3$ & $5.9 \pm 23$ & $8.55 \pm 10$ & $24.8 \pm 4.2$ & $0.05 \pm 19$ & $0.43 \pm 23$ & $2.21 \pm 9.6$ & $1.72 \pm 12$ \\
\hline & & A14 & $59.9 \pm 2.5$ & $5.04 \pm 21$ & $8.67 \pm 9.2$ & $23.8 \pm 4.5$ & $0.09 \pm 22$ & $0.57 \pm 13$ & $2.00 \pm 15$ & $2.80 \pm 12$ \\
\hline & Cellulosic & N13 & $47.9 \pm 5.1$ & $0.86 \pm 17$ & $6.52 \pm 6.3$ & $43.6 \pm 5.1$ & $0.12 \pm 22$ & $0.40 \pm 31$ & $0.78 \pm 11$ & $8.31 \pm 8.5$ \\
\hline & & A14 & $44.5 \pm 3.1$ & $1.70 \pm 15$ & $6.33 \pm 5.9$ & $46.4 \pm 3.8$ & $0.32 \pm 46$ & $0.07 \pm 27$ & $1.00 \pm 20$ & $9.00 \pm 9.4$ \\
\hline & Textile & N13 & $53.2 \pm 2.1$ & $2.41 \pm 11$ & $4.52 \pm 8.6$ & $33.7 \pm 3.0$ & $0.06 \pm 24$ & $0.36 \pm 29$ & $5.79 \pm 7.8$ & $2.07 \pm 5.5$ \\
\hline & & A14 & $58.7 \pm 2.9$ & $1.11 \pm 19$ & $4.77 \pm 7.3$ & $30.8 \pm 6.2$ & $0.24 \pm 32$ & $0.56 \pm 16$ & $4.00 \pm 27$ & $3.30 \pm 17$ \\
\hline & Plastics & A14 & $71.3 \pm 1.4$ & $0.23 \pm 13$ & $10.7 \pm 4.5$ & $3.09 \pm 7.8$ & $0.06 \pm 21$ & $0.62 \pm 9.2$ & $14.0 \pm 16$ & $0.20 \pm 47$ \\
\hline \multirow[t]{2}{*}{ Bulky global } & Aver. Val. & N13 & 51.11 & 2.15 & 6.32 & 37.93 & 0.09 & 0.40 & 2.09 & 5.46 \\
\hline & & A14 & 52.86 & 2.01 & 6.67 & 35.20 & 0.24 & 0.33 & 2.93 & 5.79 \\
\hline
\end{tabular}

Table 3

Elemental analysis, chlorine, ash and moisture content for wastes received in November 2013 (N13) and April 2014 (A14) (wt.\%, dry basis).

Average \pm relative standard deviations (\%) based on $n=2$ during elemental analysis, moisture and ash determination and $n=3$ during chlorine determination.

a Wet basis of material. 


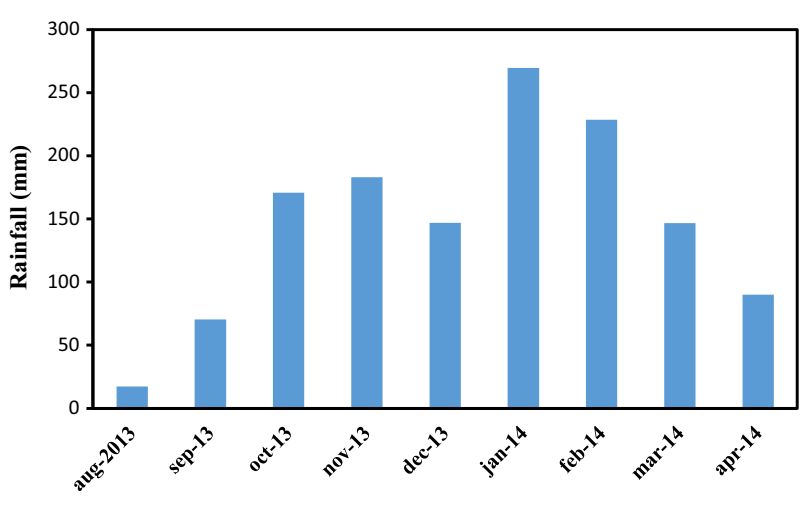

Fig. 2. Average rainfall during the months prior to sampling (AEMET, 2014).

bulky wastes, no marked differences are observed between both sampling months (November 2013 vs April 2014). In both cases, the highest moisture content of the cellulosic fractions is remarkable, observation already found by Velis et al. (2012) in the analysis of solid fuels produced by mechanical-biological treatment of municipal wastes. The average values here obtained, between 1.23 and $7.09 \mathrm{wt} . \%$, are considerable lower than the upper limit for moisture content (15 wt.\%) for cement kilns (EURITS, 2000; Velis et al., 2012).

The ash content of the bulky waste varies between 2 and 3 wt.\% depending on the seasonability, being the textile fraction the highest contribution, as it could be expected. The packaging waste exhibits ash content higher than the previous waste, due mainly to both the textile and the cellulosic fractions. This agrees with studies on domestic wastes, where the ash content in paper and textiles were larger than for any other combustible (Ryu, 2010). Furthermore, the differences observed in both sampling moments could be justified attending to the predominant packaging like tetrabricks in the November 2013 composition data, whereas in the April 2014's one, the major constituent becomes the textile. The standard deviations for this kind of waste are usually quite high, since the waste composition may change throughout the year according to the population behavior. Concerning the ash content in the ELV waste, great differences were observed between the samples taken in November 2013 and April 2014. These differences could be due to the presence of fines and few traces of soil with high ash content up to 36.2 wt.\% (Mirabile et al., 2002). Thus, once analyzed the fine fraction of the ELV waste, these high ash content traces were removed from the fractions analyzed in April 2014.

Table 3 includes also the elemental analyses of the different wastes. In all the components, it is observed that the major contribution of $\mathrm{C}$, followed by $\mathrm{O}$ to the total elemental analysis, being the plastics the fraction with the highest contribution of carbon, in agreement with previous works about this type of materials (Wagland et al., 2011). For the plastic fraction of the ELV waste, carbon content varies between 76.50 and $78.20 \mathrm{wt}$ \% depending on the sampling moment. For the ELV wastes, most of the plastic components are made of polypropylene (PP), polyurethane (PUR), polyvinylchloride (PVC), acrylonitrile butadiene styrene (ABS), poly-methyl-methacrylate (PMMA) and polyethylene terephthalate (PETE) (Vermeulen et al., 2011). This type of plastics may have carbon contents up to $79.0 \mathrm{wt}$ \% in the case of PP (Komilis et al., 2012). In the case of the textile fraction and the fractions of foams, the seasonability factor is not observed and carbon content varies between 53.2 and 58.7 wt.\%, and between 52.8 and 59.9 wt.\%, respectively, in agreement with other similar researches where Construction and Industrial Wastes (C\&IW) were studied (57.4 and 62.5 wt.\%, respectively) (Nasrullah et al., 2014). In the case of the cellulosic fractions, there are no significant differences between samples taken in November 2013 and April 2014 and the results are comparable with those obtained in previous works with a carbon content of 50.7 wt.\% in the case of mixed wood waste, and $46.8 \mathrm{wt} . \%$ in the case of paper waste (Burnley et al., 2011). For the packaging waste, the carbon content of the packaging, soft plastic and cellulosic fractions are comparable with data obtained in other studies with carbon contents of $81.8 \mathrm{wt} . \%$ for packaging and soft plastics and $40.3 \mathrm{wt}$.\% for the cellulosic fraction (Adrados et al., 2013). Oxygen is the next element, being especially dominant in all the fractions with the exception of plastics as can be observed in previous studies about this type of wastes (Komilis et al., 2012). According to these works, the oxygen content in the plastic fraction varies between 2.3 and $5.0 \mathrm{wt} . \%$ depending on the physical properties of the plastic material (Nasrullah et al., 2014) although the presence of types of plastics as PETE, present in the ELV and packaging wastes and with an oxygen content up to 32.7 wt.\% (Komilis et al., 2012), may increase oxygen content. The textile fractions and the fractions of foams have a moderate oxygen content, between 19.8 and $21.3 \mathrm{wt}$.\% according to previous studies (Nasrullah et al., 2014). For other hand, the cellulosic fractions analyzed have the highest oxygen content with values between 30.3 and $54.0 \mathrm{wt} . \%$. These values are comparable with data obtained in other works (Adrados et al., 2013)). Seasonal variation of the oxygen content in the cellulosic fraction for the packaging waste could be due to the variation of ash content, as oxygen content is calculated by difference according to Eq. (1). Hydrogen is the next most predominant element but it is only relevant in the case of plastic fractions and, to a lesser extent, in foams. According to some works, hydrogen content in plastics could vary from $4.32 \mathrm{wt} . \%$ in the case of PETE to $14.4 \mathrm{wt} . \%$ in the case of PP (Komilis et al., 2012). For foams, hydrogen content may reach 8.4 wt.\% (Nasrullah et al., 2014), this value is similar to data obtained in this study (between 7.15 and $8.67 \mathrm{wt} . \%$ ). In the case of nitrogen and sulfur content, both values obtained as those found in other researches are low $(<1 \%$, in most cases) compared to the other elements.

Regarding to chlorine content, it is quite low in most cases, below $1 \mathrm{wt}$ \%; being these wastes suitable for industrial combustion at moderate temperatures $\left(850^{\circ} \mathrm{C}\right)$. If chlorine content were higher, it would be necessary to raise the temperature to $1100{ }^{\circ} \mathrm{C}$ (Directive 2000/76/EC of the European Parliament and of the Council of 4th December 2000 on the incineration of waste). The packaging waste collected in April 2014 has a very high chlorine content, this fact could be due to the presence of traces of PVC from fragments of pipe found particularly in this waste. PVC also appears in food packaging although it is used less and less. In the case of the ELV waste and according to different works, the chlorine content of ASR ranges from 0.5 to $4 \mathrm{wt}$.\% and is mainly due to the presence of chlorinated plastic components such as PVC or halobutyl rubber (Vermeulen et al., 2011).

Regarding to heavy metal content, Table 4 shows the limit concentration of each one of the heavy metals whose regulation is recommended by European Union for responsible incineration and treatment of special waste agency (EURITS) for co-incineration of waste in cement kilns. Heavy metal concentration mean values for each type of waste are also shown in Table 4. For the fine fraction of the ELV waste, the concentration limits of $\mathrm{Cr}, \mathrm{Mn}, \mathrm{Ni}, \mathrm{Cu}, \mathrm{Zn}$, $\mathrm{Mo}$ and $\mathrm{Pb}$ are exceeded. Such high metal concentrations have been observed in previous works (Mirabile et al., 2002; Vermeulen et al., 2011) for the fine fraction of the ELV waste with particle size $<2 \mathrm{~mm}$. This fact prevents the use of this fraction as SRF. In the case of the ELV waste, only significant concentrations of $\mathrm{Cu}, \mathrm{Zn}$ and $\mathrm{Pb}$ were obtained. It is quite usual to find these metals in a car. $\mathrm{Pb}$ is present in the batteries, $\mathrm{Zn}$ is one of the constituents of the galvanized steel used in the bodywork of cars and $\mathrm{Cu}$ is the main element of the electrical wiring of the car. In 
Table 4

Limit concentration of heavy metal in SRF according to EURITS, 2000 and heavy metal concentration values for each sort of waste (mg $\mathrm{kg}^{-1}$ ).

\begin{tabular}{|c|c|c|c|c|c|c|c|c|}
\hline \multirow[t]{2}{*}{ Metal } & \multirow[t]{2}{*}{ EURITS standard } & \multicolumn{4}{|c|}{ November 2013} & \multicolumn{3}{|l|}{ April 2014} \\
\hline & & ELV fine & ELV & Packaging & Bulky & ELV & Packaging & Bulky \\
\hline V & 200 & $39.2 \pm 2.1$ & $5.17 \pm 2.0$ & $3.30 \pm 1.8$ & $1.00 \pm 12$ & $1.80 \pm 10$ & $0.60 \pm 20$ & $0.45 \pm 15$ \\
\hline $\mathrm{Cr}$ & 200 & $529 \pm 11$ & $112 \pm 1.8$ & $9.67 \pm 14$ & $2.72 \pm 21$ & $14.6 \pm 12$ & $41.6 \pm 24$ & $2.49 \pm 5.2$ \\
\hline Mn & 200 & $582 \pm 1.8$ & $114 \pm 16$ & $35.3 \pm 4.3$ & $65.6 \pm 12$ & $42.3 \pm 12$ & $26.4 \pm 12$ & $35.9 \pm 10$ \\
\hline Co & 200 & $19.3 \pm 9.8$ & $4.86 \pm 1.9$ & $1.25 \pm 1.7$ & $0.52 \pm 15$ & $2.72 \pm 2.2$ & $0.41 \pm 20$ & $2.40 \pm 2.4$ \\
\hline $\mathrm{Ni}$ & 200 & $486 \pm 1.5$ & $76.3 \pm 2.4$ & $7.00 \pm 2.5$ & $7.33 \pm 3.1$ & $16.1 \pm 2.5$ & $10.3 \pm 4.2$ & $3.66 \pm 2.0$ \\
\hline $\mathrm{Cu}$ & 200 & $6713 \pm 2.5$ & $603 \pm 2.8$ & $20.9 \pm 2.3$ & $24.3 \pm 10$ & $44.2 \pm 16$ & $10.7 \pm 10$ & $4.65 \pm 2.8$ \\
\hline $\mathrm{Zn}$ & 500 & $2146 \pm 2.0$ & $985 \pm 2.4$ & $79.7 \pm 16$ & $56.0 \pm 12$ & $1216 \pm 6.8$ & $49.9 \pm 4.2$ & $61.5 \pm 3.2$ \\
\hline As & 10 & $0.74 \pm 12$ & $1.63 \pm 2.3$ & $0.31 \pm 4.2$ & $0.35 \pm 12$ & $1.25 \pm 30$ & $0.29 \pm 28$ & $0.18 \pm 20$ \\
\hline $\mathrm{Se}$ & - & $0.04 \pm 0.0$ & $0.34 \pm 5.6$ & $0.04 \pm 0.0$ & $0.04 \pm 0.0$ & $0.08 \pm 4.5$ & $0.15 \pm 6.4$ & $0.07 \pm 26$ \\
\hline Mo & - & $56.2 \pm 12$ & $18.2 \pm 26$ & $0.88 \pm 15$ & $1.75 \pm 32$ & $9.30 \pm 3.2$ & $0.08 \pm 20$ & $0.07 \pm 26$ \\
\hline $\mathrm{Cd}$ & 10 & $2.61 \pm 19$ & $0.94 \pm 15$ & $0.17 \pm 15$ & $0.11 \pm 20$ & $0.58 \pm 48$ & $0.21 \pm 14$ & $0.18 \pm 24$ \\
\hline $\mathrm{Sb}$ & 10 & $6.67 \pm 4.3$ & $7.39 \pm 2.5$ & $9.15 \pm 1.4$ & $1.75 \pm 42$ & $22.7 \pm 1.3$ & $17.4 \pm 9.4$ & $9.98 \pm 7.4$ \\
\hline $\mathrm{Hg}$ & 2 & $0.07 \pm 0.0$ & $0.08 \pm 0.0$ & $0.01 \pm 0.0$ & $0.12 \pm 0.0$ & $1.93 \pm 1.5$ & $1.03 \pm 5.0$ & $1.99 \pm 5.0$ \\
\hline $\mathrm{Tl}$ & 2 & $0.08 \pm 3.0$ & $0.04 \pm 5.0$ & $0.02 \pm 0.0$ & $0.02 \pm 0.0$ & $0.03 \pm 0.0$ & $0.03 \pm 0.0$ & $0.05 \pm 0.0$ \\
\hline $\mathrm{Pb}$ & 200 & $1103 \pm 25$ & $838 \pm 35$ & $33.0 \pm 12$ & $42.7 \pm 41$ & $152 \pm 15$ & $19.5 \pm 18$ & $176 \pm 24$ \\
\hline
\end{tabular}

Average \pm relative standard deviations (\%) based on $n=3$ during heavy metal determination.

Table 5

HHV and LHV mean values for each fraction of waste.

\begin{tabular}{|c|c|c|c|c|c|}
\hline \multirow[t]{2}{*}{ Waste } & \multirow[t]{2}{*}{ Fraction } & \multicolumn{2}{|c|}{ HHV Nov‘13 LHV Nov`13 } & \multicolumn{2}{|c|}{ HHV April'14 LHV April'14 } \\
\hline & & (MJ dry $\mathrm{kg}^{-1}$ ) & $\left(\mathrm{MJ}\right.$ wet $\mathrm{kg}^{-1}$ ) & $\left(\right.$ MJ dry $\mathrm{kg}^{-1}$ ) & $\left(\mathrm{MJ}\right.$ wet $\mathrm{kg}^{-1}$ ) \\
\hline \multirow[t]{4}{*}{ ELV } & Fine & $10.22 \pm 0.01$ & 9.60 & n.a & n.a \\
\hline & Plastics & $35.44 \pm 1.29$ & 33.05 & $46.79 \pm 0.48$ & 39.95 \\
\hline & Foams & $26.79 \pm 0.73$ & 24.62 & $28.74 \pm 1.21$ & 26.22 \\
\hline & Textile & $18.14 \pm 2.38$ & 16.82 & $28.67 \pm 0.23$ & 26.89 \\
\hline \multirow[t]{4}{*}{ Packaging } & Packaging & $29.80 \pm 0.69$ & 26.46 & $23.67 \pm 0.25$ & 21.19 \\
\hline & Soft plastics & $40.32 \pm 9.54$ & 37.50 & $45.17 \pm 3.71$ & 41.78 \\
\hline & Cellulosic (paper) & $16.57 \pm 1.29$ & 14.03 & $18.41 \pm 1.99$ & 16.50 \\
\hline & Textile & $22.09 \pm 0.74$ & 20.80 & $28.03 \pm 0.31$ & 25.48 \\
\hline \multirow[t]{4}{*}{ Bulky } & Foams & $26.95 \pm 2.24$ & 24.68 & $28.53 \pm 0.80$ & 25.92 \\
\hline & Cellulosic (wood) & $18.62 \pm 2.15$ & 15.78 & $20.15 \pm 0.68$ & 17.08 \\
\hline & Textile & $24.38 \pm 9.08$ & 22.91 & $20.75 \pm 0.88$ & 19.06 \\
\hline & Plastics & n.a & n.a & $42.35 \pm 0.54$ & 39.99 \\
\hline
\end{tabular}

Average \pm relative standard deviations (\%) based on $n=2$ during HHV determination.

previous articles, ranges of heavy metal concentrations for ELV waste have been found for $\mathrm{Pb}, 0-5000 \mathrm{mg} \mathrm{kg}^{-1}$; $\mathrm{Cu}, 1000-$ $6000 \mathrm{mg} \mathrm{kg}^{-1}$; Zn, 0-15,000 $\mathrm{mg} \mathrm{kg}^{-1}$; and $\mathrm{Cr}, 100-200 \mathrm{mg} \mathrm{kg}^{-1}$ (Viganò et al., 2010). These ranges are comparable with data obtained in this study. In the case of the ELV waste received in April 2014, Cu and $\mathrm{Pb}$ limits were not exceeded as these concentrations could change depending on the process of separating of the different fractions. On the other hand, the packaging and bulky wastes present metal contents clearly below these limits. For the bulky waste, similar heavy metal concentrations have been obtained in other studies (Jung et al., 2004). In this study, chromium content varies between 2.49 and $2.72 \mathrm{mg} \mathrm{kg}^{-1}$ for the bulky waste whereas, in previous studies, chromium content reaches $15.1 \mathrm{mg} \mathrm{kg}^{-1}$. This fact could be due to the absence of rubber, power cords and electric circuit boards in the bulky waste analyzed since these fractions are the largest contributors to chromium content (Jung et al., 2004). In the case of copper content, values obtained varies between 4.65 and $24.30 \mathrm{mg} \mathrm{kg}^{-1}$. This seasonable variation could be due to the presence of traces of electric wires. However, these values are far removed from those found in the literature $\left(10,648 \mathrm{mg} \mathrm{kg}^{-1}\right)$ as there are some fractions which have not been found in the waste studied (i.e.: power cords, electric circuit boards). On the other hand, in this study, lead content varies between 42.7 and $175.8 \mathrm{mg} \mathrm{kg}^{-1}$ in agreement with previous works (Jung et al., 2004).

Table 5 contains the mean higher and lower heating values (combustion enthalpy) expressed on dry and wet basis, respec- tively, for each waste fraction analyzed. Table 5 shows that all the plastic fractions have the highest heating values, followed by the fractions of foams, the textile components and the cellulosic fractions having the ELV fine fraction the lowest heating value, discarding this fraction for use as SRF. These results are similar to those found in previous studies (Nasrullah et al., 2014; Montejo et al., 2011) where, in the case of the plastic fractions, LHV varies between 35.0 and $37.0 \mathrm{MJ} \mathrm{kg}^{-1}$ (Nasrullah et al., 2014) whereas, in this study, LHV for this type of fractions varies between 33.05 and $39.99 \mathrm{MJ} \mathrm{kg}^{-1}$. This variation could be due to the type of plastic. The HHV of plastics as PET could reach $23.00 \mathrm{MJ} \mathrm{kg}^{-1}$ and, in the case of HDPE (high density polyethylene), its value is $45.67 \mathrm{MJ} \mathrm{kg}^{-1}$ according to other works (Montejo et al., 2011). In the case of the fractions of foams, LHV could reach $27.3 \mathrm{MJ} \mathrm{kg}^{-1}$ (Nasrullah et al., 2014) obtaining similar results in this study. The packaging fractions, despite being a type of plastic fraction, have lower heating values due to the presence of other type of plastic as PETE used in the manufacture of bottles and tetrabricks with a HHV of $23.56 \mathrm{MJ} \mathrm{kg}^{-1}$ (Montejo et al., 2011). These sort of plastics have a lower carbon content and therefore, their heating contents are lower (Komilis et al., 2012). The differences found between the fractions corresponding to the months of November 2013 and April 2014 were due to the differences of elemental composition between these fractions and, in the case of the ELV waste, the presence of different types of plastics with higher calorific values for the waste collected in April 2014 has meant an increase of LHV. 


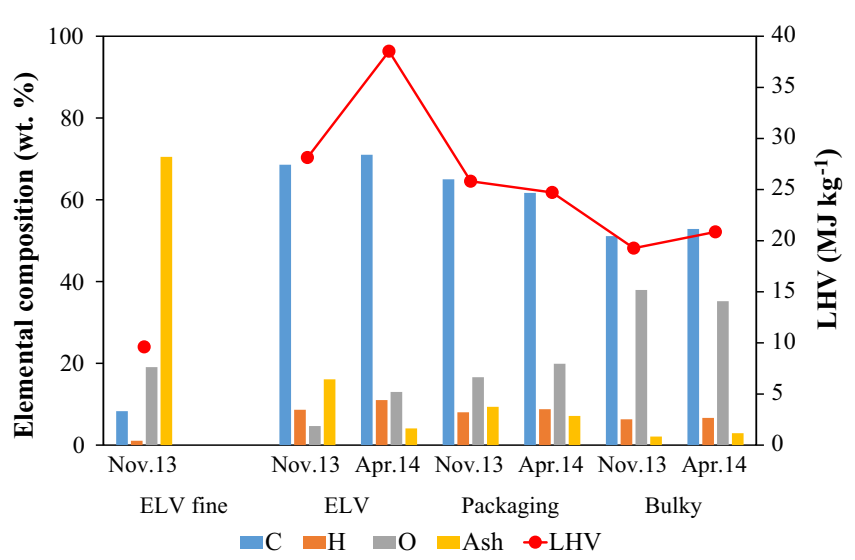

Fig. 3. Elemental composition and lower heating values of the wastes considered in this work.

Fig. 3 shows the influence of the elemental composition of the different waste fractions on LHV experimental data. According to these figures, the higher the percentage of carbon and hydrogen in the waste, the higher the LHV will be. However, those compounds with higher oxygen and ash content have a lower calorific value (i.e.: the fine fraction of the ELV waste). Therefore, the calorific value of the ELV waste collected in November 2013 is lower than the collected in April 2014 since the sum of the hydrogen and carbon contents is higher for the ELV waste collected in April 2014 than for the ELV waste collected in November 2013.

\subsection{Waste classification}

Table 6 summarizes the parameter values for classification of the different wastes as SRF. According to these data together with criteria established in Table 1, the class code of each waste is also shown in Table 6.

From the point of view of the heating value, the most important parameter for the classification of SRF, the ELV waste is the best suited for use as SRF followed by the packaging waste, bulky waste and, finally, the fine fraction of the ELV waste. In view of the results, chlorine content is the key parameter. In the case of the packaging waste received in April 2014, the chlorine content is unusually high and cannot be classified as SRF. The development of a more efficient separation technique that removes PVC plastic parts could cause a decrease in chlorine content in this waste allowing its use as SRF.

On the other hand, Table 6 also shows the average value of the parameters studied on a global waste consisting of a mixture of the three wastes analyzed considering the amount processed of each one of them at COGERSA facilities. As mentioned above, the amounts generated of each one of the wastes studied from COGERSA facilities in 2013 were 17,410 tons of ELV waste, 7186 tons of bulky waste and 3277 tons of packaging waste. Once calculated the average fractional composition between the two periods of the year analyzed, the global waste obtained would have the following composition: $43.43 \mathrm{wt} . \%$ in plastics, $24.20 \mathrm{wt} . \%$ in textile, $15.51 \mathrm{wt} . \%$ in cellulosic fraction, $11.79 \mathrm{wt} . \%$ in foams and $5.08 \mathrm{wt}$. $\%$ in packagings. This waste has much lower chlorine content than the packaging waste collected in April 2014, lower than 1\% because of the packaging waste is generated in a lower proportion than the others resulting in a global waste suitable for its use in cement kilns. The concentration of chlorine in SRF is key to fuel quality, since elevated chlorine concentrations exacerbate ash deposition in the convective part of boilers; cause high-temperature corrosion $\left(>500{ }^{\circ} \mathrm{C}\right)$ of boiler steel due to alkali chlorides and lower temperature melt deposits $\left(300-400^{\circ} \mathrm{C}\right)$ in the presence of zinc and lead; generate high acid gases emissions $(\mathrm{HCl})$; and contribute to the formation of polychlorinated dibenzodioxins (PCDDs) during thermal recovery (Velis et al., 2012). In the case of mercury, during combustion, it is generally found in three forms, namely, particle-bound, gaseous elemental mercury and in oxidized form. At high temperature in the combustion zone, $\mathrm{Hg}$ vaporizes into the elemental form, which is toxic to humans. With a temperature reduction, it is oxidized by flue gas components forming $\mathrm{HgCl}_{2}$ and $\mathrm{HgO}$. A small fraction of $\mathrm{Hg}$ can also be condensed on ash particles due to temperature reduction (Wagland et al., 2011).

Comparing the wastes measured with the characteristics of the other SRFs studied in previous works, significant matches have been found. In Spain, Ramos Casado et al. (2016) analyzed a SRF solid fuel with the following elemental composition: $51.7 \mathrm{wt} . \% \mathrm{C}$, 7.0 wt.\% H, 17.94 wt.\% O, 1.20 wt.\% N, 0.30 wt.\% S, 0.76 wt.\% Cl and $21.1 \mathrm{wt} . \%$ ash. With a LHV of $20.34 \mathrm{MJ} \mathrm{kg}^{-1}$, this SRF is similar to the bulky waste studied in this work with respect to elemental composition, as shown in Table 3, having a LHV between 19.27 and $20.86 \mathrm{MJ} \mathrm{kg}^{-1}$ although oxygen content is higher in this study due to the lower ash content. In Finland, Bajamundi et al. (2015) analyzed two SRF solid fuels to be used as co-fuel in fluidized bed boilers, with an elemental composition similar to the bulky waste analyzed in this study, and with an oxygen content (27.529.1 wt.\%) alike that found in this study (35.20-37.93 wt.\%).

The use of such wastes as SRF could report cost savings of raw materials and significant economic benefits. According to the annual amount of these three types of wastes generated in COGERSA facilities (27,873 t/year in 2013) and with an average LHV for these wastes of $28.15 \mathrm{MJ} \mathrm{kg}^{-1}$ as shown in Table 6 , the heat generated in the combustion of these wastes was calculated. This value is equivalent to that generated in the combustion of 22,976 tons of petroleum coke as the LHV for petroleum coke is $34.15 \mathrm{MJ} \mathrm{kg}^{-1}$ (Cement Kilns, 2015). As an example, it corresponds to a $20 \%$ of the total energy consumption of a cement kiln close to COGERSA facilities with a total consumption of petroleum coke of $117,000 \mathrm{t} /$ year (2013).This decline in consumption of petroleum coke also represents GHG emission reduction. The total emission of $\mathrm{CO}_{2}$ for petroleum coke is $3254 \mathrm{~kg} \mathrm{CO}_{2} \mathrm{~kg}^{-1}$ (cementkilns.co. $\mathrm{uk}$, while for MSW, the total emission of $\mathrm{CO}_{2}$ is $1170 \mathrm{~kg} \mathrm{CO}$

Table 6

Key parameters values and classification as SRF.

\begin{tabular}{|c|c|c|c|c|c|c|c|c|}
\hline \multirow[t]{2}{*}{ Parameter } & \multicolumn{4}{|c|}{ November 2013} & \multicolumn{3}{|c|}{ April 2014} & \multirow[t]{2}{*}{ Average value } \\
\hline & ELV fine & ELV & Packaging & Bulky & ELV & Packaging & Bulky & \\
\hline LHV $\left(\mathrm{MJ} \mathrm{kg}^{-1}\right)$ & 9.60 & 28.13 & 25.81 & 19.27 & 35.89 & 24.91 & 20.86 & 28.15 \\
\hline NCV class & 5 & 1 & 1 & 3 & 1 & 2 & 2 & 1 \\
\hline $\mathrm{Cl}(\%)$ & 0.12 & 0.63 & 0.10 & 0.09 & 0.10 & 6.28 & 0.24 & 0.68 \\
\hline $\mathrm{Cl}$ class & 1 & 3 & 1 & 1 & 1 & $>5^{\mathrm{a}}$ & 2 & 3 \\
\hline $\mathrm{Hg} \cdot 10^{3}\left(\mathrm{mg} \mathrm{MJ}^{-1}\right)$ & 7.32 & 2.76 & 0.39 & 6.22 & 50.21 & 41.35 & 95.40 & 32.10 \\
\hline Hg class & 1 & 1 & 1 & 1 & 3 & 3 & 3 & 3 \\
\hline
\end{tabular}

a This value exceeds to the value corresponding to Class 5. 
Table 7

Higher heating value: empirical models (Kathiravale et al., 2003) and comparison between experimental data and predicted HHV.

\begin{tabular}{|c|c|c|c|c|c|}
\hline \multirow[t]{2}{*}{ Model } & \multirow[t]{2}{*}{ Equation } & \multicolumn{2}{|c|}{ November 2013} & \multicolumn{2}{|l|}{ April 2014} \\
\hline & & $\mathrm{SSR}^{\mathrm{a}}$ & $R^{2}$ & $\mathrm{SSR}^{\mathrm{a}}$ & $R^{2}$ \\
\hline Dulong & $\mathrm{HHV}=81 \mathrm{C}+342.5(\mathrm{H}-0 / 8)+22.5 \mathrm{~S}-6(9 \mathrm{H}-\mathrm{W})$ & $13,119,441$ & 0.858 & $34,003,587$ & 0.707 \\
\hline Scheurer-Kestner & $\mathrm{HHV}=81(\mathrm{C}-3 / 4 \mathrm{O})+342.5 \mathrm{H}+22.5 \mathrm{~S}+57(3 / 4) \mathrm{O}-6(9 \mathrm{H}-\mathrm{W})$ & $8,332,580$ & 0.865 & $21,923,627$ & 0.693 \\
\hline Steuer & $\mathrm{HHV}=81(\mathrm{C}-3 / 80)+57(3 / 8) \mathrm{O}+345(\mathrm{H}-\mathrm{O} / 10)+25 \mathrm{~S}-6(9 \mathrm{H}-\mathrm{W})$ & $13,254,878$ & 0.857 & $34,203,358$ & 0.708 \\
\hline Chang & $\mathrm{HHV}=8561.11+179.72 \mathrm{H}-63.89 \mathrm{~S}-111.17 \mathrm{O}-91.11 \mathrm{Cl}-66.94 \mathrm{~N}$ & $49,042,395$ & 0.443 & $10,624,486$ & 0.828 \\
\hline
\end{tabular}

C, H, O, S, W, Cl and N: carbon, hydrogen, oxygen, sulfur, moisture, chlorine and nitrogen content (wt.\%).

a Sum of the squares of the residuals.

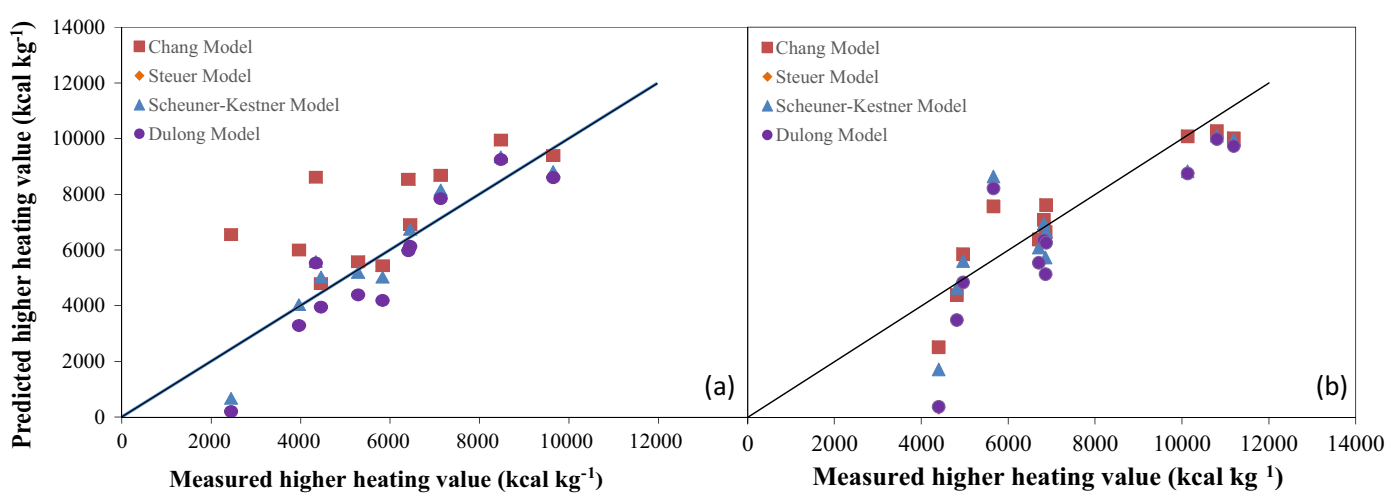

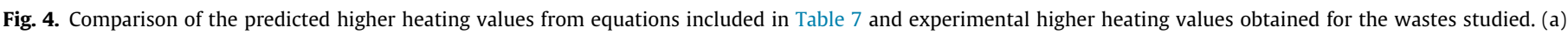
November 2013. (b) April 2014.

$\mathrm{kg}^{-1}$ (Psomopoulos, 2014). Considering the amount of wastes available and the amount of petroleum coke replaced, indicated above, $\mathrm{CO}_{2}$ emissions can be highly reduced over $40,000 \mathrm{t} / \mathrm{year}$.

\subsection{Empirical modeling}

Table 7 shows four empirical models used for describing HHV as a function of the elemental composition. In the case of Dulong model, initially, the original model was developed to predict the HHV for coal but, once modified, it is also used for predicting the HHV for MSW as well as the other three models. According to Dulong, Scheurer-Kestner and Steuer models, carbon, hydrogen, oxygen and sulfur are the main predictors of calorific value. However, in the case of the Chang model, carbon is not a predictor of HHV but chlorine and nitrogen are present in this model. These models show positive values of the carbon and hydrogen coefficients and negative value of the oxygen coefficient. The positive correlation of calorific value and carbon and hydrogen content and the negative correlation of calorific value and oxygen content are evident in Fig. 3 and can be explained by the fact that elemental $O$ does not contribute to the energy content of an organic substrate, since oxygen itself cannot be combusted. And, generally, the higher the oxygen content of a material, the lower are the carbon and hydrogen contents, the both contribute to the energy content (Komilis et al., 2012).

According to the magnitude of the coefficients of the equations included in Table 7, hydrogen has the highest relative contribution to the prediction of the HHV, followed by carbon and then by oxygen, except in the case of Chang model which does not include carbon in its regression model. It is worth mentioning that the coefficients of $\mathrm{C}$ and $\mathrm{H}$ in the Dulong model are very similar to the corresponding coefficients in the Scheurer-Kestner and Steuer models. The coefficient of $\mathrm{O}$ in the Scheurer-Kestner model is lower than the coefficient of $\mathrm{O}$ in the Dulong and Steuer models. In the case of the Chang model, the coefficient of $\mathrm{H}$ is lower than in the other models and the coefficients of $\mathrm{S}$ and $\mathrm{O}$ are much higher compared to that in the other models being the contribution of sulfur in the Chang model positive, unlike the other models.

Fig. 4 shows a comparison between the HHV predicted by empirical models and the experimental HHV found for each fraction of the wastes analyzed. Table 7 also includes the sum of squares of the residuals (SSR) and the $R^{2}$ values for the four models studied. For the waste fractions collected in November, ScheurerKestner model resulted the lowest SSR and the highest $R$ value among all the models, indicating that it provides the best fit to the data. As shown in Table 7, Scheurer-Kestner model is a little better fitted to the elemental data compared to Dulong and Steuer models, since it achieves the highest $R$ value and S-K model is quite better predictive tool since it has a lower SSR value than the other models. Liu et al. (1996) found experimental heating data for MSW were more similar to results obtained using ScheurerKestner equation $\left(R^{2}=0.70\right)$ than other equations as Steuer model $\left(R^{2}=0.56\right)$ and Dulong formula $\left(R^{2}=0.58\right)$. However, for the waste fractions collected in April 2014, Chang model resulted in the lowest SSR and the highest $R$ value among all the models. This fact, a priori, contradicts what happened in the corresponding samples to November 2013 but, observing the elemental composition of the samples collected in April 2014, there are two fractions with high chlorine content (the packaging and textile fractions of the packaging waste) whose estimated HHV is far from the experimental one except using the Chang model, which is the only one that considers the contribution of the chlorine content. In addition, the HHV of the cellulosic fraction of the packaging waste collected in April 2014 is not well predicted by the Dulong, 
Scheurer-Kestner and Steuer models because of its low carbon content. However, according to Chang model, carbon does not contribute to HHV and, therefore, the value predicted by this model is most approximated to experimental data.

\section{Conclusions}

The ELV waste has a higher LHV being, from this point of view, the most suitable candidate for use as SRF, followed by the packaging and bulky waste. On the other hand, the fine fraction of the ELV waste has the lowest LHV and is discarded for use as SRF. The ELV waste also exceeds the limit concentration for $\mathrm{Cu}, \mathrm{Zn}$ and $\mathrm{Pb}$, since these heavy metals are very common in different components of a car (copper wires, galvanized pieces, batteries). Due to that, more efficient separation techniques could be necessary to be used this waste as SRF. According to Directive 2000/53/EC of the European Parliament and of the Council of 18th September 2000 on end-of life vehicles, no later than 1 January 2015, for all end-of life vehicles, the reuse and recovery shall be increased to a minimum of $95 \%$ by an average weight per vehicle and year. Following this recommendation, it would be very interesting that this type of waste could be used as SRF. (Page 19 Line 23 to Page 20 Line 6).

On the other hand, the fine fraction of the ELV waste breach the much heavy metal concentration limits recommended by EURITS. This fact together with the poor calorific value make that this fraction is not recommended for use as SRF. As for the content of mercury, the bulky waste collected in April 2014 have the highest concentration among the wastes studied followed by the packaging and ELV wastes collected in April 2014, but none of these wastes exceeds the concentration recommended by EURITS.

As for the content of chlorine, satisfactory results have been obtained as the overall waste formed by the sum of the generated amounts of the three wastes generated has chlorine level below limit of $1 \%$ dictated by Directive 2000/76/EC of the European Parliament and of the Council of 4th December 2000, making it a suitable solid recovered fuel. However, taking into account the three wastes measured by separated as potential SRFs, the packaging waste collected in April 2014 has a chlorine content 6 times higher than that established by the regulations and could not be used as SRF. On the other hand, the rest of wastes having a chlorine content within established limits.

Chang equation and Scheurer-Kestner model are the most approximate to the experimental values in each case. Chang equation is that best fits to experimental data for the fractions corresponding to April 2014. However, Scheurer-Kestner model is the most approximate to the experimental HHV from the wastes collected in November. This fact is due to the high chlorine content in some of the fractions corresponding to the wastes collected in April 2014 since this equation is the only one that includes the chlorine content in its formula.

In conclusion, SRF-grade solid fuels can be obtained by blending of the different wastes studied in this work with a LHV of $28.15 \mathrm{MJ} \mathrm{kg}^{-1}$, a chlorine content of $0.68 \mathrm{wt}$.\% and a mercury content of $3.33 \times 10^{-2} \mathrm{mg} \mathrm{MJ}^{-1}$ resulting a class code $\mathrm{NCV} 1 \mathrm{Cl} 3 \mathrm{Hg} 3$. Other possibility would be using the different wastes analyzed as SRF by separated except the packaging waste collected in April 2014, with a very high chlorine content. Further improvements in the collection of these wastes (avoiding PVC and metals in the wastes) will lead to an increase of the fuel quality.

\section{Acknowledgments}

This work was supported by COGERSA (contract Waste-toFuel). Waste-to-Fuel project (IE13-084) was partly supported by Plan for Science, Technology and Innovation of Asturias (PCTI) and European Regional Development's fund (FEDER). Diego Garcés thanks the Government of the Principality of Asturias for a Ph.D. fellowship (Severo Ochoa Program).

\section{References}

Adrados, A., De Marco, I., Lopez-Urionabarrenechea, A., Caballero, B.M., Laresgoiti, M.F., 2013. Pyrolysis behavior of different type of materials contained in the rejects of packaging waste sorting plants. Waste Manage. 33, 52-59.

AEMET, 2014. Spanish Meteorology National Agency. <http://www.aemet.es/es/ serviciosclimaticos/vigilancia_clima/resumenes $>$ (accessed 03.04.15).

Arena, U., Gregorio, F., 2014. A waste management planning based on substance flow analysis. Resour., Conserv. Recycl. 85, 54-66.

Bajamundi, C.J.E., Vainikka, P., Hedman, M., Silvennoinen, J., Heinanen, T., Taipale, R. Konttinen, J., 2015. Searching for a robust strategy for minimizing alkali chlorides in fluidized bed boilers during burning of high SRF-energy-share fuel. Fuel 155, 25-36.

Burnley, S., Phillips, R., Coleman, T., Rampling, T., 2011. Energy implications of the thermal recovery of biodegradable municipal waste materials in the United Kingdom. Waste Manage. 31, 1949-1959.

Cement Kilns, 2015. <http://www.cementkilns.co.uk/data_coke.html> (accessed 07.07.15).

EN 15359 Solid recovered fuels, 2013. Specifications and classes. <http://www aenor.es> (accessed 2013).

EN 15400 Solid recovered fuels, 2013. Determination of calorific value. <http:// www.aenor.es> (accessed 2013).

EN 15407 Solid recovered fuels, 2013. Methods for the determination of carbon (C), hydrogen $(\mathrm{H})$ and nitrogen $(\mathrm{N})$ content. <http://www.aenor.es> (accessed 2013).

EN 15408 Solid recovered fuels, 2013. Methods for the determination of sulphur (S), chlorine $(\mathrm{Cl})$, fluorine $(\mathrm{F})$ and bromine $(\mathrm{Br})$ content. <http://www.aenor.es> (accessed 2013).

EN 15411 Solid recovered fuels, 2013. Methods for the determination of the content of trace elements (As, Ba, Be, Cd, Co, Cr, Cu, Hg, Mo, Mn, Ni, Pb, Sb, Se, Tl, V and $\mathrm{Zn}$ ). <http://www.aenor.es> (accessed 2013).

EN 15413 Solid recovered fuels, 2013. Methods for the preparation of the test sample from the laboratory sample. <http://www.aenor.es> (accessed 2013).

Environment Protection Agency, Ireland, Municipal Waste Characterisation, 1996 <https://www.epa.ie/pubs/reports/waste/wastecharacterisation/ EPA_municipal_waste_characterisation.pdf> (accessed 15.04.15).

EURITS "European Union for Responsible Incineration and Treatment of Special Waste". <http://ec.europa.eu/environment/waste/studies/pdf/rdf.pdf> (accessed 06.05.14)

European Commission, 2008. Directive 2008/98/EC of the European Parliament and of the Council of 19 November 2008 on waste. <http://eur-lex.europa.eu/legalcontent/EN/TXT/?uri=CELEX:32008L0098> (accessed 19.12.14).

Eurostat, 2013. <http://ec.europa.eu/eurostat/tgm/refreshTableAction.do?tab= table\&plugin $=1$ \&pcode $=$ tsdpc240\&language $=e n>($ accessed 06.05.15).

Jung, C.H., Matsuto, T., Tanaka, N., Okada, T., 2004. Metal distribution in incineration residues of municipal solid waste (MSW) in Japan. Waste Manage. 24, 381-391.

Kathiravale, S., Yunus, M.N.M., Sopian, K., Samsuddin, A.H., Rahman, R.A., 2003. Modeling the heating value of municipal solid waste. Fuel 82, 1119-1125.

Komilis, D., Evangelou, A., Giannakis, G., Lymperis, C., 2012. Revisiting the elemental composition and the calorific value of the organic fraction of municipal solid wastes. Waste Manage. 32, 372-381.

List of Wastes (LOW), 2014. <http://eur-lex.europa.eu/legal-content/EN/TXT/?uri= uriserv:OJ.L_.2014.370.01.0044.01.ENG> (accessed 06.05.15).

Liu, J.I., Paode, R.D., Holsen, T.M., 1996. Modeling the energy content of Municipal Solid Waste using multiple regression analysis. J. Air Waste Manage. Assoc. 46, 650-656.

Lombardi, L., Carnevale, E., Corti, A., 2015. A review of technologies and performances of thermal treatment systems for energy recovery from waste. Waste Manage. 37, 26-44.

Mirabile, D., Pistelli, M.I., Marchesini, M., Falciani, R., Chiappelli, L., 2002. Thermal valorisation of automobile shredder residue: injection in blast furnace. Waste Manage. 22, 841-851.

Montejo, C., Costa, C., Ramos, P., Márquez, M.C., 2011. Analysis and comparison of municipal solid waste and reject fraction as fuels for incineration plants. Appl. Therm. Eng. 31, 2135-2140.

Nasrullah, M., Vainikka, P., Hannula, J., Hurme, M., Kärki, J., 2014. Mass, energy and material balances of SRF production process. Part 1: SRF produced from commercial and industrial waste. Waste Manage. 34, 1398-1407.

Psomopoulos, C.S., 2014. Residue derived fuels as an alternative fuel for the hellenic power generation sector and their potential for emissions reduction. AIMS Energy 2, 321-341.

Psomopoulos, C.S., Vanetis, I., Themelis, N.J., 2014. The impact from the implementation of "waste-to-energy" to the economy. A macroeconomic approach for the trade balance of Greece. Fresenius Environ. Bull. 23 (11), 2735-2741.

Rada, E.C., Andreottola, G., 2012. RDF/SRF: which perspective for its future in the EU. Waste Manage. 32 (6), 1059-1060.

Rada, E.C., Ragazzi, M., Apostol, T., 2008. Role of refuse derived fuel in the Romanian industrial sector after the entrance in EU. WIT Trans. Ecol. Environ. 109, 89-96. 
Rada, E.C., Squazardo, L., Ionescu, G., Badea, A., 2014. Economic viability of SRF cocombustion in cement factory. UPB Sci. Bull., Ser. D 76 (3), 199-206.

Ragazzi, M., Rada, E.C., 2012. RDF/SRF evolution and MSW bio-drying. WIT Trans Ecol. Environ. 163, 199-208.

Ramos Casado, R., Arenales Rivera, J., Borjabad García, E. Escalada Cuadrado, R. Fernández Llorente, M., Bados Sevillano, R., Pascual Delgado, A., 2016. Classification and characterisation of SRF produced from different flows of processed MSW in the Navarra region and its co-combustion performance with olive tree pruning residues. Waste Manage. 47, 206-216.

Ruiz Romero, S., Colmenar Santos, A., Castro Gil, M.A., 2012. EU plans fo renewable energy. An application to the Spanish case. Renew. Energy 43, 322-330.

Ryu, C., 2010. Potential of municipal solid waste for renewable energy production and reduction of greenhouse gas emissions in South Korea. J. Air Waste Manage. Assoc. 60, 176-183.

Samolada, M.C., Zabaniotou, A.A., 2014. Energetic valorization of SRF in dedicated plants and cement kilns and guidelines for application in Greece and Cyprus. Resour., Conserv. Recycl. 83, 34-43.

Sánchez, M.E., Otero, M., Gómez, X., Morán, A., 2009. Thermogravimetric kinetic analysis of the combustion of biowastes. Renew. Energy 34, 1622-1627.
Telmo, C., Lousada, J., 2011. Heating values of wood pellets from different species. Biomass Bioenergy 35, 2634-2639.

Tsiliyannis, C.A., 2012. Alternative fuels in cement manufacturing: modeling for process optimization under direct and compound operation. Fuel 99, 20-39.

Velis, C. Wagland, S., Longhurst, P. Robson, B., Sinfield, K., Wise, S., Pollard, S., 2012 Solid recovered fuel: influence of waste streams composition and processing on chlorine content and fuel quality. Environ. Sci. Technol. 46, 1923-1931.

Vermeulen, I., Van Caneghem, J., Block, C., Baeyens, C., Vandecasteele, C., 2011. Automotive shredder residue (ASR): reviewing its production from end-of-life vehicles (ELVs) and its recycling, energy or chemicals' valorisation. J. Hazard. Mater. 190, 8-27.

Viganò, F. Consonni, S., Grosso, M. Rigamonti, L., 2010. Material and energy recovery from automotive shredded residues (ASR) via sequential gasification and combustion. Waste Manage. 30, 145-153.

Virmond, E., De Sena, R.F., Albrecht, W., Althoff, C.A., Moreira, R., José, H.J., 2012 Characterisation of agroindustrial solid residues as biofuels and potential application in thermochemical processes. Waste Manage. 32, 1952-1961.

Wagland, S.T., Kilgallon, P., Coveney, R., Garg, A., Smith, R., Longhurst, P.J., Pollard, S.J. T. Simms, N., 2011. Comparison of coal/solid recovered fuel(SRF) with coal/refuse derived fuel (RDF) in a fluidised bed reactor. Waste Manage. 31, 1176-1183. 